\title{
O Cairo pela metade
}

\author{
George Martine*
}

\section{Introdução}

Imagino que, para muitas pessoas, o título deste ensaio estaria sinalizando a lentidão do progresso na implementação do Programa de Ação definido na Conferência do Cairo, em relação aos temas de equidade de gênero, saúde sexual e reprodutiva (SSR) e aborto. Ou poderia estar referindo-se aos vieses na organização do evento "Cairo+25", pois, conforme destacado em outros trabalhos desta edição da Rebep, a estruturação e temática deste evento sinalizam um retraso político e substantivo. Tais interpretações seriam perfeitamente compreensíveis. Entretanto, o que pretendo fazer neste texto é outra coisa. Proponho-me a refletir sobre o abandono de um componente central da proposta original da Conferência Internacional sobre População e Desenvolvimento (CIPD), ou seja, a agenda "população e desenvolvimento" propriamente dita. Desde o Cairo, persiste um teor maniqueísta na interpretação das prioridades e caminhos apontados pelo Programa de Ação (PoA), resultando numa disputa por espaço e recursos, assim como na perda de eficácia da agenda proposta. Considero que isso tem enfraquecido, inadvertidamente, tanto o processo de desenvolvimento sustentável como a implementação mais efetiva das propostas inovadoras do PoA.

Este texto é baseado em 20 anos de atuação profissional em torno dos temas relevados no PoA da CIPD, refletindo explicitamente minhas próprias experiências, atitudes, reflexões e frustrações sobre esta matéria. Em que consiste minha experiência com a trajetória da CIPD? Trata-se essencialmente da minha vivência profissional como consultor, funcionário e colaborador do Fundo de População das Nações Unidas (UNFPA). Esta entidade - por ser organizadora da CIPD e executora do PoA, por ter influência política como agência das Nações Unidas e por ser fonte de recursos para a implementação do PoA - tem sido o principal norteador da sua interpretação.

\footnotetext{
* Consultor independente, Brasília-DF, Brasil (georgermartine@yahoo.com; https://orcid.org/0000-0001-5876-2540).
} 


\section{Origem e evolução da agenda UNFPA}

A criação do UNFPA, no final da década de 1960, foi influenciada pela preocupação dos países desenvolvidos com o crescimento populacional global e pela vontade de se ter uma entidade multilateral mais "neutra" e respeitada nas discussões que ardiam sobre o controlismo. A atividade principal do UNFPA, até a CIPD, era a promoção do planejamento familiar, que, entre outros benefícios, levaria à estabilização do crescimento populacional. Para tornar sua presença e sua proposta mais aceitáveis nos países em desenvolvimento, o Fundo oferecia também uma série de apoios para coleta de dados, treinamento de pessoal, equipamentos, assistência técnica, pesquisas, etc. Estes apoios eram agregados numa área programática chamada de "população e desenvolvimento" (P e D) e facilitavam as iniciativas da entidade nos terrenos mais controversos e delicados relacionados ao planejamento familiar. Esperava-se que o conjunto destes apoios levaria eventualmente o país a formular uma "política de população".

No decorrer da década de 1980, tive a oportunidade de participar de debates sobre o tema de políticas populacionais com Nafis Sadik, do UNFPA, em vários foros internacionais. Apesar das críticas que eu fazia ao seu viés controlista, o UNFPA me contratou para algumas consultorias internacionais e, em 1992, me encomendou um "strategy paper" abordando tendências globais e perspectivas para o trabalho futuro do Fundo. ${ }^{1}$ Essencialmente, meu texto destacava a redução dramática da fecundidade global, exceto na África, e argumentava que o UNFPA, para garantir seu nicho, precisaria estender seu foco central para além do planejamento familiar e da estabilização populacional. Destacava, inter alia, uma série de questões em que a dinâmica populacional interagia com processos de desenvolvimento, analisava as limitações do planejamento familiar visto como política de população e registrava a mudança de foco, que já se observava no Brasil e alhures, do "planejamento familiar" para a "saúde integral da mulher".

Apesar das críticas da Dra. Sadik, o texto acabou gerando uma boa discussão interna na sede do UNFPA durante o pré-Cairo. Realizei mais algumas consultorias e aceitei, em 1996, um convite para trabalhar como especialista em "população, desenvolvimento e meio ambiente" na equipe de apoio técnico do UNFPA para América Latina e Caribe. Passei a servir como diretor deste grupo regional entre 1998 e 2003. Posteriormente, fui consultor externo do UNFPA de 2003 a 2013. O conjunto destas experiências serve de base para as observações que se seguem.

\section{Prioridades e ambiguidades no PoA}

Em retrospecto, pode ser observado que o maniqueísmo que persiste em alguns círculos, em relação à interpretação intelectual, política e pragmática do PoA, tem suas

\footnotetext{
${ }^{1}$ MARTINE, G. The changing world scenario and challenges for technical assistance: selected aspects in the population field. New York: UNFPA, 1992, $51 \mathrm{p}$.
} 
raízes numa certa ambiguidade do próprio texto. De fato, este englobou duas agendas bem diferenciadas num guarda-chuva conceitual chamado de "população e desenvolvimento".

Por um lado, o PoA retomava a literatura demográfica e econômica da época para enfatizar, no primeiro capítulo substantivo do texto (capítulo 3), a necessidade de integrar "population concerns" nas estratégias, no planejamento, nas decisões e na alocação de recursos, com o objetivo de melhorar a qualidade de vida desta e de futuras gerações, promover a justiça social e erradicar a pobreza. Esta recomendação é a mais genérica do PoA e está explicitada em oito dos seus 12 capítulos substantivos, em que se destacam ações necessárias em várias questões, incluindo crescimento populacional, estrutura etária, urbanização, dados, migração e desenvolvimento sustentável.

Por outro lado, o PoA oferecia um paradigma desbravador para a área de população, negando políticas controlistas baseadas em objetivos quantificados e colocando os direitos, escolhas e saúde da mulher no cerne da questão. Isso representava um marco histórico para a equidade de gênero, direitos reprodutivos e direitos humanos e oferecia uma plataforma extraordinária para movimentos sociais nestas questões. Tratava-se de uma nova análise da situação, de uma agenda pioneira e de recomendações inovadoras dentro de uma perspectiva de direitos. Curiosamente, apesar de ter pouca relação com a agenda anterior do UNFPA em população e desenvolvimento, estas questões foram também englobadas no guarda-chuva chamado "população e desenvolvimento" - talvez para amenizar a oposição a uma agenda política focada em direitos.

Em suma, o conceito "população e desenvolvimento" do PoA reunia duas agendas bastante díspares que podemos denominar, para fins heurísticos, como "planejamento" e "direitos", respectivamente. A primeira era baseada na expansão e aprimoramento de uma área programática do UNFPA, buscando apoiar a pesquisa e o planejamento em prol de políticas do tipo macro. A outra era inovadora, focada em temas e propostas pioneiras para a ação política, capaz de mobilizar diversas categorias sociais, especialmente o movimento de mulheres. Supostamente, o fator unificador entre essas duas agendas seria a ênfase na questão de direitos. Entretanto, a caracterização e implementação de direitos eram óbvias, imediatas e conectadas diretamente a movimentos sociais numa vertente, enquanto na vertente "planejamento" essa integração era complexa, opaca e apoiada apenas por um lobby difuso.

Esta dupla perspectiva incitou interpretações diferenciadas sobre as prioridades para a ação do UNFPA no pós-Cairo. O PoA sugeria uma atuação muito mais compreensiva no planejamento do que a área programática de $\mathrm{P}$ e $\mathrm{D}$ mantida pelo UNFPA no pré-Cairo, mas não explicava como a questão de direitos se aplicaria concretamente nestas atividades. Nas áreas de gênero e saúde reprodutiva, a energia dos movimentos sociais, que tinha sido decisiva na preparação e realização do Cairo, favorecia um maior investimento do UNFPA nestas questões, embora houvesse ainda dificuldades na identificação de atividades para serem financiadas, fora da área de advocacy. Também, a reticência do UNFPA de 
se comprometer com grupos políticos ou temas mais progressistas, como saúde sexual e aborto, limitava a margem de ação que ousava financiar.

Neste período, a cúpula do UNFPA, assim como os diretores regionais e diretores de país, ficava dividida sobre a melhor forma de implementar a agenda de direitos e atender às demandas dos países. ${ }^{2}$ Alguns funcionários oriundos da demografia ou economia tendiam a trabalhar mais com setores governamentais da área de planejamento, oferecendo preferencialmente apoios financeiros e técnicos mais tradicionais para a implementação do capítulo 3. Entretanto, a rejeição dos movimentos de mulheres aos modelos quantitativos e à utilização de dados para justificar posturas controlistas criava obstáculos para tais iniciativas. Por outro lado, o próprio "envelhecimento" de algumas recomendações do PoA impedia avanços. De fato, com o tempo, alguns capítulos do "planejamento" foram se tornando ultrapassados ou profundamente equivocados, como é o apoio ao crescimento econômico sustentado ou a condenação da urbanização. Faltavam recursos intelectuais, humanos e financeiros para elevar e atualizar a área tradicional de P e D. Enquanto isso, os propósitos inovadores da agenda gênero/SSR do Cairo geravam mais entusiasmo e, nesta conjuntura, passavam a comandar os recursos e as atividades do UNFPA.

\section{Tentativas de reequilibrar a agenda}

A equipe de apoio técnico do UNFPA que eu dirigia naquela época não estava alheia a esta discussão e se preocupava, em parte, não apenas com a implementação do capítulo 3 e de sua conexão com a agenda de direitos, mas também com a desatualização das análises no campo programático $P$ e $D$. Na tentativa de revitalizar essa agenda e equilibrar as ações na instituição, elaboramos, com Ralph Hakkert e José Miguel Guzman, vários trabalhos e organizamos várias reuniões. Nosso objetivo era mostrar a necessidade de incrementar o aporte da área programática de "planejamento", até porque esta era necessária para sustentar a própria luta pelo exercício de direitos. Argumentamos que a melhor compreensão dos processos sociodemográficos em curso e a implementação de políticas populacionais coerentes com esse conhecimento teriam uma influência positiva na capacidade das pessoas em terem e aproveitarem escolhas, tanto nos domínios de gênero e saúde reprodutiva, como numa variedade de outros domínios que afetariam seu bem-estar.

Procuramos convencer o UNFPA da necessidade de inserir estes esforços atualizados na totalidade do "guarda-chuva" de P e D, tal como recomendado pelo PoA. Esta perspectiva acabou ganhando espaço, primeiro, na divisão da América Latina e, posteriormente, na política institucional, particularmente no mandato de Thoraya Obaid na direção do UNFPA.

\footnotetext{
$\overline{2}$ Esta ambivalência pode ser ilustrada por um incidente que ocorreu quando eu realizava uma missão no Haiti no período pós-Cairo. Naquele momento, o país não dispunha de nenhuma informação sociodemográfica recente e não tinha como fazer planejamento de áreas críticas como saúde, educação, habitação, etc. Portanto, sugeri que o UNFPA apoiasse urgentemente a realização de um censo, ou pelo menos uma contagem rápida, a fim de poder estabelecer alguns parâmetros básicos para a ação pública. Entretanto, a diretora de país negou qualquer iniciativa deste tipo com o argumento de que, "depois do Cairo, estamos interessados em pessoas e não em números".
} 
Obaid promoveu um movimento de reforma da agência e participei, junto com Rogelio Fernandes e outros, do Strategic Direction Team que liderava esse processo. 0 relatório final da equipe recomendava, de forma contundente, a necessidade de recolocar as questões de $\mathrm{P}$ e D, tal como previsto no PoA, no centro da agenda institucional. ${ }^{3}$

Nos anos posteriores, já como consultor ad-hoc, pude observar que esta visão continuava tendo espaço formal na postura institucional, mas as atividades e os recursos não acompanhavam estes avanços, apesar dos esforços de especialistas em postos-chave, como Rogelio Fernandes e Jose Miguel Guzman, e de alguns resultados positivos. ${ }^{4} \mathrm{Em}$ 2012, fui convidado para escrever o documento-base sobre P e D para o Comitê Interagencial que preparava a posição do secretário geral na plenária da ONU, na celebração de Cairo+20. 0 discurso inaugural deste evento, em 2014, retomava pontos importantes da postura do PoA em população e desenvolvimento. Mas, apesar destes momentos e instâncias positivas, a área programática do "planejamento" tem sido progressivamente minimizada no UNFPA ao longo dos últimos anos, estando agora em níveis inferiores aos que existiam no período pré-Cairo.

A nomeação do Dr. Babatunde para o posto de secretário executivo do UNFPA, em 2010, foi marco importante neste declínio. Apoiado pelos doadores internacionais do Fundo que continuavam preocupados com o crescimento da população africana, Babatunde não valorizava os aportes do P e D. Sua sucessora e ex-assessora, Natalia Kanen, está aparentemente sendo até mais incisiva nesta postura. A quebra com o mandato e a atuação tradicional do UNFPA ficam surpreendentemente destacadas no site do Fundo, onde se declara, sumariamente, que "o UNFPA é a agência das Nações Unidas para saúde sexual e reprodutiva”! Em seguida, o texto destaca dez áreas de atuação, sendo que apenas a última da lista - a coleta de dados - se deriva, e de maneira instrumental, da área "planejamento". Não se encontra aí nenhuma palavra referente ao objetivo mais genérico do PoA, nem aos oito capítulos que o sustentavam.

Essa perda de espaço para uma massa crítica e para atividades da vertente "planejamento" não tem permitido a atualização essencial de muitos propósitos do PoA. Como a maioria das agências da ONU, o UNFPA continua assinando, acriticamente, as iniciativas em favor do crescimento econômico sustentado (e insustentável), deixa de se preocupar com as interfaces entre dinâmica populacional e sustentabilidade e se omite praticamente em

\footnotetext{
3 "The Fund should define a more strategic role for its work in population and development [...] The stakeholder analysis indicates that, after ICPD, the Fund's activities in this domain became less focused. Recent emphasis on poverty reduction has reinvigorated interest in P\&D, making it imperative for UNFPA to exploit its comparative advantage as the only operational UN agency with a specific mandate in the population domain, and to play a significant role in the analysis of demographic trends and their socio-economic policy implications". UNFPA. Strategic direction positioning statement. New York: Strategic Direction Team, UNFPA, May 2002.

${ }^{4}$ A perda de oportunidades ficou particularmente marcante para mim quando consegui - a duras penas e com certa oposição interna - convencer o UNFPA a centrar seu State of the World Population 2007 na urbanização. Apesar de esta publicação oferecer uma proposta original e bem recebida (é preciso preparar para o massivo e inevitável crescimento urbano, em vez de combatê-lo) e ter gerado enorme interesse da grande imprensa, com mais de 200 mil downloads apenas nas primeiras três semanas e estimulado uma proposta inédita de projeto conjunto pelo Banco Mundial, inter alia, o tema foi praticamente abandonado, não gerando nenhuma ação concreta na sequência.
} 
relação a temas sociodemográficos críticos da atualidade, como a migração, a urbanização e as mudanças na composição populacional. Seu mandato nestas temáticas lhe confere uma enorme responsabilidade e sua omissão, particularmente neste cenário conturbado de desgovernança nacional e global, é grave.

Em suma, a importância dos processos econômicos, ecológicos e demográficos na configuração do ambiente no qual os direitos básicos podem vigorar e se expandir tem sido gravemente subestimada. 0 objetivo central da área de "planejamento" hoje seria justamente o de esclarecer as condições estruturais que facilitam o exercício de direitos e a melhoria do bem-estar social. Na realidade, abraçar a visão mais ampla e atualizada da agenda beneficiaria a todos os segmentos do PoA, até para a consecução de recursos para a totalidade do "guarda-chuva P e D". Nesse sentido, portanto, urgem uma revisão e atualização das propostas do PoA e sua integração não somente nas atividades do UNFPA, mas também em eventos como a celebração de Cairo+25.

\section{Referências}

HAKKERT, R.; MARTINE, G. Population, poverty and inequality: a Latin American perspective. In: UNFPA. Population and poverty: achieving equity, equality and sustainability. New York, NY, 2003. p. 101-126. (Population and Development Strategies, Series n. 8). ISBN 978-0897146654.

MARTINE, G. O contraste entre o desenvolvimento sustentável na CIPD e a realidade atual. In: RODRÍGUEZ WONG, L. et al. (org.). Cairo+20: perspectivas de la agenda de población y desarrollo sostenible después de 2014. Rio de Janeiro, RJ: Alap Editora, 2013. p. 213-224. (Serie Investigaciones, n. 15). ISBN 978-85-62016-19-6.

MARTINE, G. ICPD beyond 2014: thematic paper on Population Dynamics for ICPD Review Global Report Thematic Group. New York: UNFPA, May 2013. 32 p.

MARTINE, G. ICPD+20 and beyond: elements of a strategy for UNFPA/LACRO. (Project rla6a14a/ activity 04). Final report. Panama City: UNFPA Country Support Team, 2010. 47 p.

MARTINE, G. State of world population 2007: unleashing the potential of urban growth. New York: UNFPA, 2007. 99p.

MARTINE, G. O papel dos organismos internacionais na evolução dos estudos populacionais no Brasil: notas preliminares. Revista Brasileira de Estudos de População, São Paulo, v. 22, n. 2, p. 257-275, 2005.

MARTINE, G. Institutionalizing strategic thinking, planning and management. Contributions to UNFPA's Strategic Direction Task Force. New York: UNFPA, 2002. 11 p.

MARTINE, G.; HAKKERT, R.; GUZMAN, J. M. Population and development in the context of UNFPA: responding to new challenges (with Ralph Hakkert and Jose Miguel Guzman). Mexico: UNFPA/ CST, 2003. 36 p.

UNFPA. Programme of Action. Adopted at the International Conference on Population and Development, Cairo 5-13 September, 1994. UNFPA, 2004. 166 p. 


\section{Sobre 0 autor}

George Martine é sociólogo/demógrafo com doutorado pela Brown University e M. A. da Fordham University. Ex-presidente da Associação Brasileira de Estudos Populacionais (Abep), membro sênior do Harvard Center for Population and Development, diretor da equipe técnica do UNFPA para a América Latina e o Caribe e diretor do Instituto de Sociedade, População e Natureza, entre outros. Atualmente, trabalha como consultor em questões de desenvolvimento social, população e meio ambiente.

\section{Endereço para correspondência}

SHIS QI 19/6/20

71655-060 - Brasília-DF, Brasil

Recebido para publicação em 29/10/2019

Aceito para publicação em 30/10/2019 